\begin{tabular}{|c|c|c|}
\hline $\begin{array}{c}\text { ISSN 2525-4812 (versão online) } \\
\text { ISSN 2238-7641 (versão impressa) } \\
\text { http://www.revistaterceiramargem.com/ } \\
\text { index.php/terceiramargem/index }\end{array}$ & $\begin{array}{c}\text { Recebido em: 3/9/2019 } \\
\text { Aprovado em: 17/5/2020 } \\
\text { Período de publicação: jan., } 2021\end{array}$ & $\begin{array}{c}\text { Revista Terceira } \\
\text { Margem Amazônia } \\
\text { (v. } 6 \cdot \text { n. especial } 16 \cdot \text { Jan. } 2021 \text { ) }\end{array}$ \\
\hline
\end{tabular}

Como citar o artigo:

AUBERTIN, C; JESUS, L. M. K de. A contribuição do Brasil na COP21: o agronegócio do futuro. Revista Terceira Margem Amazônia. v. 6, n. especial 16, p. 35-52, 2021. DOI: http://dx.doi.org/10.36882/2525-4812.2021v6i16.ed.esp.p35-52

\title{
A CONTRIBUIÇÃO DO BRASIL NA COP21: O AGRONEGÓCIO DO FUTURO ${ }^{1,2}$
}

Catherine Marie Aubertin ${ }^{3}$

Livia Maria Kalil de Jesus ${ }^{4}$

Resumo: Ao estudar a contribuição do Brasil na Convenção das Nações Unidas sobre as alterações climáticas para a COP21 (INDC), mostramos como o País afirma tanto a sua soberania quanto uma dupla postura de quem está fazendo o dever de casa e é líder na arena internacional. A queda do desmatamento na Amazônia permitiu ao Brasil reduzir suas emissões de gases de efeito estufa, mas mascarou o aumento das emissões em todos os outros setores. Ao deixar de realizar uma transição energética efetiva, a contribuição apoia todos seus esforços em um "agronegócio do futuro" sem romper com o modelo político baseado na exportação de commodities agrícolas. Analisamos aqui a contribuição brasileira como marco de um modelo político nacional aplicado sob a perspectiva de uma nova problemática representada pelo aquecimento climático.

Palavras-chave: contribuições nacionais (INDC), política energética, agronegócio, código florestal, emissões de gases de efeito estufa.

\section{BRAZIL'S INDC TO COP 21: THE AGRIBUSINESS OF THE FUTUR}

\begin{abstract}
Assessing Brazil's contribution (INDC) to the United Nations convention on climate change to COP21, we present a study showing how the country affirms both its sovereignty and dual posture as a model learner and a leader in the international arena. The decline in deforestation in the Amazon rainforest has allowed Brazil to reduce its greenhouse gas emissions while masking the increase of emissions in all other sectors. While not proposing an energy transition, the contribution made every effort to follow an "Agribusiness of the future" without undermining the political model based on the export of agricultural commodities. Here we are studying Brazil's contribution as an illustration of its national political culture in response to the problem represented by global warming.
\end{abstract}

Key words: Intended Nationally Determined Contribution (INDC), energy policy, agribusiness, Forest code, greenhouse gas emissions.

\footnotetext{
1 Este trabalho foi desenvolvido como parte do Projeto Guyamazon (FAPEAP-AIRD).

2 Uma versão desse trabalho foi publicada em francês na Revista Brésil(s), 11/2017 http://bresils.revues.org/2154.

3 Psicóloga, D. Sc. em Economia, pesquisadora do Institut de Recherche pour le Développement (IRD), Paris, França. E-mail: catherine.aubertin@ird.fr

(D) http://orcid.org/0000-0001-6030-1807

4 Socióloga, M. Sc. em Estudos Internacionais, bolsista do Centre National de la Recherche Scientifique (CNRS), Paris, França. E-mail: liviamaria.kalil@gmail.com

(D) https://orcid.org/0000-0002-5595-0340
} 


\section{Pretendida Contribuição Nacionalmente Determinada (INDC): elementos de um novo regime climático internacional}

A $21^{\text {a }}$ Conferência das Partes (COP21) da Convenção-Quadro das Nações Unidas sobre Mudança do Clima (UNFCCC), realizada em Paris em dezembro de 2015, marcou um ponto de inflexão na construção da questão climática.

Inicialmente, durante a Cúpula da Terra, no Rio de Janeiro em 1992, a questão climática havia sido tratada como uma questão de poluição, uma externalidade econômica avaliada em termos de acumulação de gases de efeito estufa (GEE) medidos em CO2 equivalente. Um acordo multilateral sob os auspícios da Organização das Nações Unidas (ONU) deveria determinar um limite de emissões desejável, buscando dividir esforços entre os países desenvolvidos para reduzir as emissões (mitigação), que, por meio do estabelecimento de um mercado internacional de carbono, poderiam ter sido alcançadas com menor custo (AUBERTIN et al. 2015).

Esse quadro foi desafiado na COP de Bali em 2007, com o surgimento dos temas "adaptação às alterações climáticas" e "dívida climática", bandeiras sustentadas pelos países em desenvolvimento. Já em 2009, em Copenhague, ele foi finalmente superado. Os países em desenvolvimento, alguns dos quais se tornaram os principais emissores de carbono, rejeitaram a prorrogação do Protocolo de Kyoto ${ }^{5}$ (que os afetaria a partir de 2012) e alegaram que não aceitariam a arbitragem política ditada pela UNFCCC. Negociar um acordo global coercitivo não poderia ser o único objetivo da convenção. Para passar de uma problemática de "partilha de encargos" a uma questão de "acesso equitativo ao desenvolvimento de baixo carbono", a lógica decrescente deu lugar a uma lógica ascendente, e cada país se comprometeu na ocasião da COP de Lima, em dezembro de 2014, a produzir uma "pretendida contribuição nacionalmente determinada" (Intended Nationally Determined Contribution, INDC - na sigla em inglês), indicando a sua estratégia frente às alterações climáticas, de acordo com suas prioridades nacionais e seus meios.

Essas contribuições nacionais se fundam sobre três princípios: a ambição (destinam-se a ir além das expectativas atuais dos Estados com um horizonte em 2020); a diferenciação (elas são examinadas levando em conta as circunstâncias nacionais de cada país); e, por fim, a transparência (tornam-se públicas por meio do site da $\mathrm{UNFCCC}^{6}$ assim que recebidas pelo secretariado). Em maio de 2016, 162 contribuições, representando 190 partes da Convenção, já haviam sido divulgadas, o que representa um êxito considerável.

Aparentemente um novo regime climático internacional pós-Kyoto começa a se formar. Este se apoia sobre as contribuições de todos os Estados, rompendo com um sistema multilateral que repartia direitos de emissões de gás de efeito estufa a serem negociados em um mercado internacional de carbono. Assim, a questão climática foi integrada às estratégias de adaptação às consequências do aquecimento global, ou seja, na escolha de um modelo de desenvolvimento incluindo suas dimensões política, econômica e social.

Apesar disso, a soma de todas as contribuições nacionais buscando reduzir as emissões de gases do efeito estufa ainda implicou em aumento da temperatura global em mais de $3,5^{\circ} \mathrm{C}$, mes-

O Protocolo de Kyoto, assinado em 1997, entrou em vigor somente em 2005. Ele exigia dos países desenvolvidos esforços para reduzir suas emissões de carbono.

${ }^{6}$ Ver http://unfecc.int/focus/indc_portal/items/8766.php (consultado dia 19 de março de 2017). 
mo levando em consideração a disponibilidade de fundos para promover as estratégias de mitigação e adaptação. Desta forma, os compromissos firmados ainda não são suficientes e estão longe de atingir o objetivo fixado pelo Acordo de Paris adotado durante a COP21, sendo ele o de manter o aquecimento global abaixo dos $2{ }^{\circ} \mathrm{C}$ até 2100 , ampliando os esforços para limitá-lo a $1,5^{\circ} \mathrm{C}$.

Diferentes grupos de trabalho internacionais internos à UNFCCC, dentro do Projeto MILES da Comissão Europeia (INSTITUTE FOR SUSTAINABLE DEVELOPMENT AND INTERNATIONAL RELATIONS, 2015) -, ou nacionais, como o Grupo Interdisciplinar sobre as Contribuições Nacionais (GICN), coordenado por Segolène Roayle (Ministra do Meio Ambiente francesa), ou ainda o Observatório do Clima no Brasil ${ }^{7}$, estudam essas contribuições prevendo suas consequências sobre as emissões de gases futuras e sobre o objetivo de temperatura planetária com a finalidade de informar aos negociadores das trajetórias nefastas que poderiam se revelar irremediáveis para o clima.

Nossa metodologia, diferentemente das supracitadas, se aproxima da sociologia política. Nós escolhemos observar as dimensões políticas e culturais das contribuições para mostrar como, a partir do caso do Brasil, elas podem dizer sobre a cultura política do país em questão.

De fato, as contribuições são relativamente livres em suas formas, permitindo a cada país apresentar a sua estratégia em um documento curto (3 páginas para a Rússia, 5 páginas para os Estados Unidos e a Europa, 10 páginas para o Brasil, 38 páginas para a Índia, etc.), oferecendo a possibilidade de se decifrar nos textos as "personalidades" desses países, no sentido de compreender a sua situação econômica e seu potencial energético, questões territoriais e de desenvolvimento, e também de identificar o desejo de aparecer no cenário mundial, de afirmar a sua identidade e soberania. Nós buscamos, então, estudar as contribuições como marcadores de uma cultura política nacional aplicada à luz da nova problemática sob a qual se apresenta o aquecimento global. Segundo Rosanvallon (2004), uma cultura política é constituída por um conjunto de traços de diferenciação que não se reduzem às diferenças institucionais, mas são também a afirmação de valores e de matrizes de comportamento. As contribuições podem assim ser interpretadas como a expressão de uma cultura política que não pode ser dissociada dos outros fenômenos político-culturais próprios a uma sociedade: "Todo sistema político aparece ligado a um sistema de valores e de representações, noutras palavras a uma cultura, característica de uma sociedade específica" (CUCHE, 2001). Esse conjunto de valores, crenças e estratégias permite que os governantes deem sentido às suas ações por intermédio de uma referência ao passado, à história e à memória coletiva, mas também à projeção de um futuro que legitima as expectativas e valoriza as escolhas de desenvolvimento (BRAUD, 2008). A contribuição do Brasil, neste caso, é exemplar.

Para analisar a contribuição brasileira, esclarecer os objetivos apresentados e confrontá-los aos fatos empíricos e em valores de viabilidade, nós nos apoiamos sobre um trabalho de campo no Brasil e sobre nosso conhecimento das políticas públicas ambientais (biodiversidade, mudanças climáticas, agroecologia). Durante a COP21, também tivemos acesso aos documentos oficiais apresentados pela delegação brasileira, observamos diferentes eventos organizados pela embaixada do Brasil e pelos representantes do agronegócio ligados à "Coalizão" (Quadro n²)

7 Ver http://www.observatoriodoclima.eco.br/ (consultado dia 19 de março de 2017). 
e também realizamos entrevistas informais. Este foi realizado dentro do Projeto ClimaCOP pesquisa colaborativa que visa propor uma cartografia dos diferentes espaços sociais da COP21 (as negociações internacionais, as empresas, a sociedade civil, as mídias) com seus atores específicos e seus discursos em tensão. Trata-se, então, de demonstrar como esses "climatizam" seus discursos, ou seja, redefinem suas ações em termos climáticos buscando uma integração com as questões científicas, ambientais, econômicas e políticas (FOYER; MORENA, 2015). Essa “climatização" seria assim própria a cada país de acordo com sua cultura política.

\section{A contribuição brasileira: o Brasil sobe ao palco}

Antes de analisar os objetivos do Brasil e como ele pretende alcançá-los, podemos constatar o desejo do País em não somente reafirmar a sua soberania, mas também a sua dupla postura de quem está fazendo seu dever de casa e de líder no palco internacional.

Isso começou com uma atenção particular à sua comunicação. O Brasil escolheu não apenas publicar a sua contribuição no site da convenção, ele escolheu the dar mais audiência. Assim, no dia 27 de setembro de 2015, em Nova York, a então presidente Dilma Rousseff leu a contribuição na ocasião da conferência das Nações Unidas sobre a Agenda 2030 a respeito das metas de sustentabilidade.

Deste modo, o Brasil se colocou como o primeiro país emergente a adotar metas absolutas de redução de emissões para toda a sua economia ${ }^{9}$. Sua contribuição não está relacionada com os pedidos de apoio financeiro internacional, ao contrário de muitos países do Sul, como Índia, Arábia Saudita, Senegal.

O Brasil não poderia celebrar suas virtudes ecológicas, como fez a Índia, cuja contribuição comporta uma citação dos Vedas sublinhando o caráter harmonioso de suas relações tradicionais com a natureza, contando também com o reforço de citações de Gandhi e referências à yoga. País de colonização recente, no qual a marcha para o Oeste se efetuou contra a floresta e as populações indígenas, era difícil para ele dissertar sobre a Mãe Natureza. Além disso, a contribuição brasileira se restringe apenas à questão da redução de gases de efeito estufa, não aborda diretamente a questão da adaptação, por exemplo: como as populações podem se prevenir dos impactos das mudanças climáticas? No entanto, um Plano Nacional de Adaptação está com consulta pública em andamento.

O Brasil deseja mostrar que já é uma economia de baixo carbono. Ele lista os seus pontos fortes: o programa de biocombustíveis "de maior sucesso mundial"; "os resultados mais impressionantes na redução do desmatamento" (82\% na Amazônia entre 2004 e 2014); uma matriz energética já composta por $40 \%$ de energias renováveis sendo "três vezes superior à média mundial, e quatro vezes maior do que a da OCDE".

\footnotetext{
8 Ver http://climacop.hypotheses.org (consultado dia 19 março de 2017).

9 Para 2030, a Índia, por exemplo, apresentou apenas uma queda na intensidade de suas emissões por ponto do PIB, de $33 \%$ a $35 \%$ em comparação a 2005, e prevê emissões de 6,2 tCO2e por habitante, o que a faz uma aluna ruim em face das recomendações do Painel Intergovernamental sobre Mudanças Climáticas (IPCC) (AUBERTIN; BENABOU, 2015). A China propôs, por sua vez, com os mesmos prazos, uma redução de $60 \%$ a $65 \%$ de suas emissões por ponto de PIB.
} 
Além disso, o País se apresenta como independente dos preceitos da convenção, salientando que os meios utilizados para alcançar sua meta de redução já fazem parte das suas políticas: a Política Nacional sobre Mudança do Clima (BRASIL, 2009), o Plano Nacional da Agricultura de Baixo Carbono (Plano ABC relacionado ao CNMA por decreto de 2010 - BRASIL, 2012), o Sistema Nacional de Unidades de Conservação (BRASIL, 2010b), o Código Florestal (reformado em 2012), o Plano Nacional de Segurança em Água (PNSH 2014).

Ele reafirma suas reservas a respeito dos mecanismos de mercado ${ }^{10}$, juntando-se à postura de recusa do presidente Lula de vender os direitos sobre a Floresta Amazônica para compensar a poluição industrial do Norte. Assim, ele disse não reconhecer qualquer transação que ocorre no seu território sem autorização e fora da convenção do Protocolo de Kyoto e do Acordo de Paris. Isso explicita a tensão entre o governo federal e os estados da Amazônia quanto à multiplicação de projetos de REDD locais provenientes de mercados voluntários sem controle fiscal e nenhuma metodologia unificada. A estratégia nacional ENREDD $+{ }^{11}$, como a lei nacional sobre o REDD+, ainda está pendente, enquanto a maioria dos estados amazônicos já promulgaram suas próprias leis sobre o REDD+, muitas vezes associadas a uma lei de pagamentos por serviços ambientais (PSA).

Finalmente uma página inteira é dedicada a uma crítica da escolha da UNFCCC para adotar a medida GWP (Potencial de Aquecimento Global) para estimar as emissões. De qualquer modo, as emissões expostas na contribuição foram recalculadas em Potencial Temperatura Global (GTP), reduzindo o aquecimento causado pelo metano da pecuária, o que, sem surpresa, faz com que seus esforços pareçam ainda maiores.

Membro do G77+ China, um país em desenvolvimento, com 15,5 milhões de pessoas abaixo da linha de pobreza, incluindo 6,2 milhões em extrema pobreza, o Brasil nunca deixa de lembrar o "princípio da equidade e das responsabilidades comuns mas diferenciadas e das capacidades respectivas, levando em conta os contextos nacionais diferenciados". Ele tem a intenção de transmitir seu modo de desenvolvimento e se oferece para apoiar as iniciativas dos países do Sul, de preferência os lusófonos.

O Brasil descreve sua contribuição como "claramente muito ambiciosa", permitindo-lhe solicitar mais esforços da parte dos países desenvolvidos. "Os esforços de mitigação do Brasil são do tipo, em escopo e em escala pelo menos, equivalente às INDCs dos países desenvolvidos, que são mais responsáveis pelas alterações climáticas do que ele, e bem além da responsabilidade marginal do Brasil no aumento da temperatura média global” (BRAZIL, 2015).

\footnotetext{
${ }^{10}$ Entretanto, o Brasil foi responsável pela iniciativa do artigo 108 do Acordo de Paris: "A Conferência das Partes reconhece o interesse social, econômico e ambiental das medidas de mitigação voluntárias e suas consequências benéficas sobre a adaptação, a saúde e o desenvolvimento sustentável" (Nações Unidas, Convenção-Quadro sobre as Mudanças Climáticas). Conferência das Partes: Relatório da Conferência das Partes sobre a vigésima primeira sessão, tida em Paris do dia 30 de novembro de 2015 ao dia 13 de dezembro de 2015. Adição: Medidas tomadas por meio da Conferências das Partes em sua vigésima primeira sessão. Disponível em http://unfccc.int/resource/docs/2015/cop21/ fre/10a01f.pdf (consultado dia 24 de março de 2017). Durante as negociações, o Brasil foi o advogado de um sistema de mecanismos de desenvolvimento próprio (MDP) entre países do Sul, propondo um sistema de preços administrados do carbono (SIRKIS et al., 2016).

${ }^{11}$ Os projetos de REDD para a redução de emissões devido ao desmatamento e à degradação das florestas consistiriam em negociar compensações para o "desmatamento evitado", ou seja, geralmente para incentivar políticas florestais virtuosas no quadro da luta contra o aquecimento global. No Brasil, os estados da Amazônia apostam nos mercados voluntários, enquanto o governo espera compensações vindas de fundos verdes da Convenção-Quadro das Nações Unidas sobre as Mudanças Climáticas (AUBERTIN 2015).
} 
Em resumo, na leitura da contribuição, entende-se que o Brasil acredita que já fez mais do que sua parte.

\section{Os seus objetivos são ambiciosos?}

O objetivo é reduzir as emissões de GEE, comparando ao ano de 2005, 37\% até 2025 (ou seja, atingir $1.300 \mathrm{MtCO} 2 \mathrm{e}$ ) e 43\% até 2030 (1.200 MtCO2), quantificadas em relação a uma situação real de referência, e não em relação a uma situação hipotética ${ }^{12}$. Em 2030, as emissões por unidade de PIB seriam reduzidas em $75 \%$ e as emissões per capita atingiram $5,4 \mathrm{tCO} 2 \mathrm{e}^{13}$, o nível mais baixo do G20, seguindo os padrões do IPCC para um aumento da temperatura média mantida abaixo de $2{ }^{\circ} \mathrm{C}$. É por isso que a contribuição do Brasil foi qualificada de ambiciosa por ele mesmo e por diversos observadores ${ }^{14}$. No entanto, a maioria das metas anunciadas já figurava em planos e programas governamentais, e a maior parte já foi atingida. O Brasil continua assim em sua trajetória de dependência, sem inflexão real em suas escolhas de desenvolvimento.

O País foi responsável por 6\% das emissões globais de GEE durante picos de desmatamento na Amazônia nos anos de 1995 e de 2004 ; já em 2012, ele emitiu apenas 3,8\%. A contribuição insiste no fato de que o Brasil conseguiu reduzir em 41\% suas emissões entre 2005 e 2012 ao passo que seu PIB cresceu $32 \%$, e 23 milhões de brasileiros deixaram a pobreza. Essa é uma dissociação notável entre crescimento e emissões de carbono. Esses resultados representam um sucesso do qual o Brasil continua a se vangloriar. No entanto, pode-se questionar atualmente a margem de manobra que o País possui para continuar a reduzir suas emissões.

Após a redução de $41 \%$ entre 2005 e 2012, uma diminuição de $43 \%$ entre 2005 e 2030 (o que corresponde a emissões de 1,2 Gt de $\mathrm{CO}_{2}$, ou seja, o nível de emissões em 2012) pode ser considerada sem ambição. Isso deve ser relativizado. Não será fácil para o Brasil conter as emissões de gases de efeito estufa em um contexto de aumento da população. O Instituto Brasileiro de Geografia e Estatística (IBGE) prevê uma população de 230 milhões de brasileiros em 2040, associado ao crescimento do PIB - previsão de 1,9\% ao ano durante o período - e também ao crescimento da renda per capita ${ }^{15}$.

Acima de tudo, a redução de $41 \%$ foi alcançada principalmente graças à queda acentuada no desmatamento na Amazônia, que passou de uma área anual desmatada de 19,014 km² em 2005 para $4.571 \mathrm{~km}^{2}$ em 2012 (INPE, 2015). Podemos dizer assim que os líderes brasileiros atravessaram um período próspero. Se a luta contra o desmatamento, em grande parte iniciada em 2004, deu os seus frutos na Amazônia, apesar de algumas retomadas localizadas, será muito mais difícil lutar contra o desmatamento no Cerrado, especialmente no que diz respeito à redução das emissões em outros setores. A luta contra o desmatamento na Amazônia foi a forma mais politicamente aceitável e o meio mais espetacular para reduzir as emissões. Em 2004, as mudanças

\footnotetext{
${ }^{12}$ Durante a COP de Copenhague de 2009, o Brasil assumiu compromissos voluntários. Tratava-se de uma janela de redução entre $36,1 \%$ e $38,9 \%$ de CO2 equivalente com base nas projeções business as usual visivelmente superestimadas para o horizonte de 2030 .

${ }^{13}$ Elas eram de 7,8 GtCOe em 2014.

${ }^{14} \mathrm{O}$ terceiro inventário das emissões entregue pelo Brasil em maio de 2016 ao secretariado da UNFCCC apresentou um forte crescimento (+ 30\%) do nível das emissões de 2005 que serve de referência. Para atingir os objetivos da INDC, a porcentagem de redução das emissões em 2025 deveria então ser de $51 \%$, e não de $37 \%$, o que reforçaria o alto nível de ambição.

${ }_{15}$ Em curto prazo, essa taxa de crescimento é bastante otimista. Em 2015, o Brasil conheceu uma recessão de 3,7\%, e o FMI previu para 2016 uma recessão de 3,5\%.
} 
no uso dos solos e das florestas representavam 77\% das emissões de CO2, e $67 \%$ das emissões de todos os gases de efeito estufa expressas em CO2e (BRASIL, 2010a). Agora, a maioria das emissões de gases de efeito estufa do Brasil não vem do desmatamento, que representa atualmente um pouco mais de um terço das emissões. Hoje, elas são majoritariamente provenientes de setores como o de energia (30,7\% por meio de transportes públicos e consumo de combustíveis fósseis) e agricultura e pecuária (26,8\%). Esses dois setores representavam em 2014 mais de 57\% das emissões (SISTEMA DE ESTIMATIVA DE EMISSÃO DE GASES DE EFEITO ESTUFA, 2015). Constatamos então que a queda do desmatamento mascarou o aumento das emissões nos outros setores (Figura 1).

Figura 1. Divisão das emissões de gases de efeito estufa por setores.

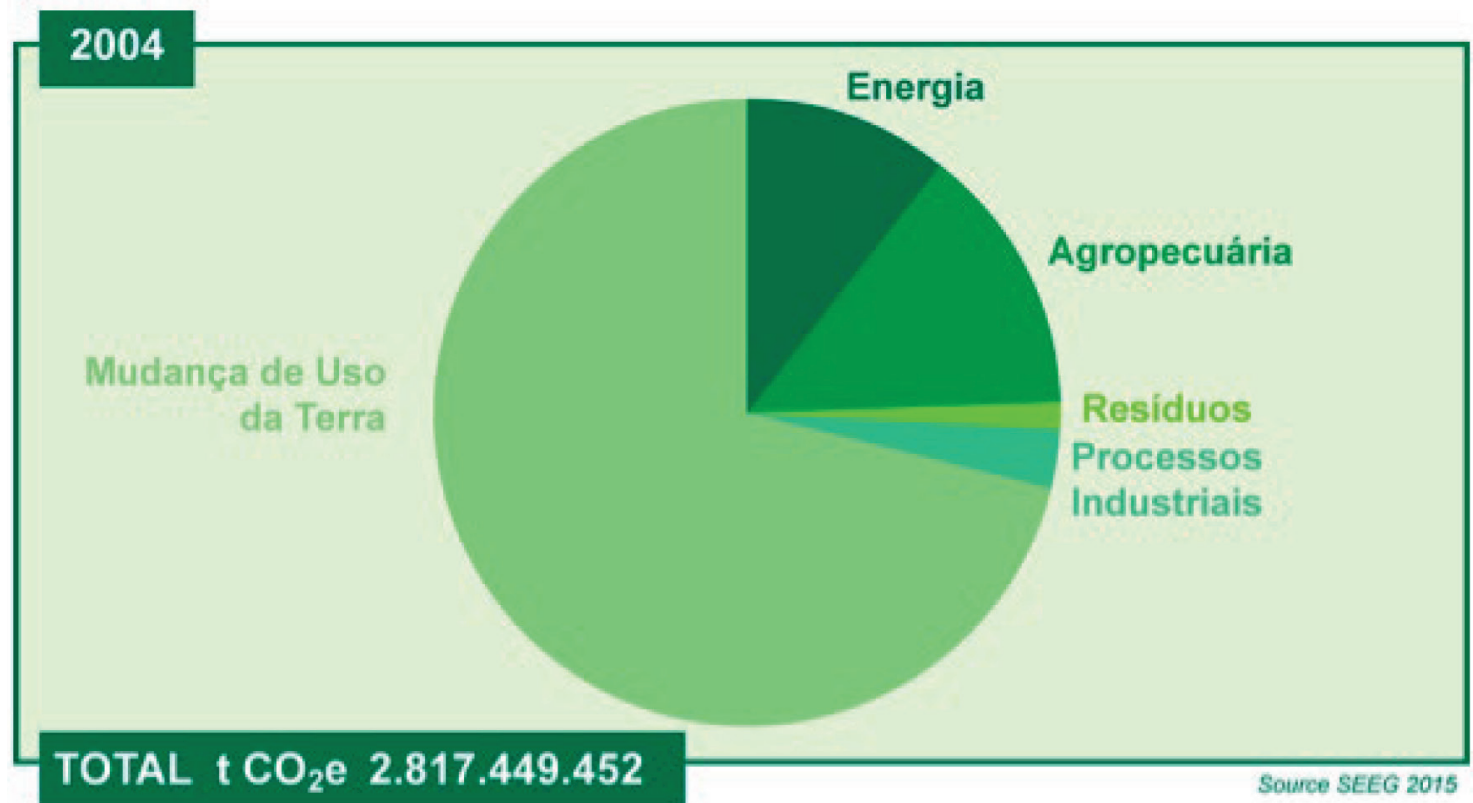

\section{4}

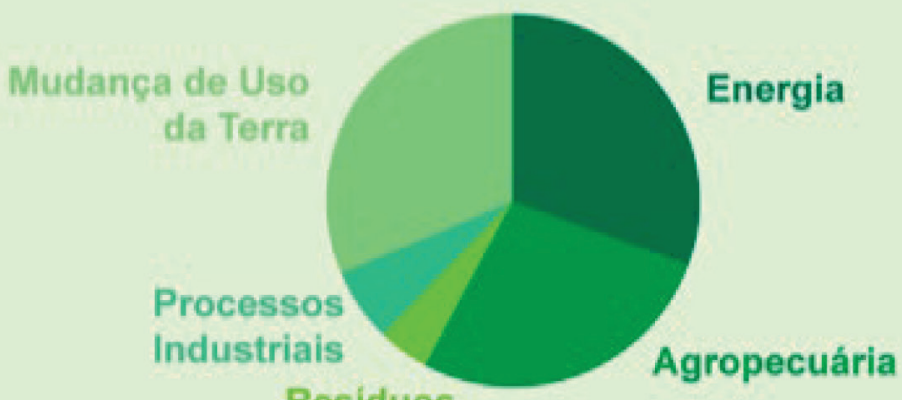

Residuos

\section{TOTAL t $\mathrm{CO}_{2}$ e 1.557.950.795}

Fonte: Essa figura foi elaborada a partir de dados brutos do sistema de estimação das emissões de gases de efeito estufa do Observatório do Clima (SISTEMA DE ESTIMATIVA DE EMISSÃO DE GASES DE EFEITO ESTUFA, 2015). De 2004 a 2014, as emissões totais do Brasil diminuíram $48 \%$. As emissões ligadas ao desmatamento caíram $67 \%$, enquanto as emissões ligadas à energia aumentaram $58 \%$, e aquelas ligadas à agricultura e pecuária cresceram $8 \%$. 


\section{As propostas que já atingem os seus limites}

A contribuição inclui “informações adicionais", indicando como alcançar os objetivos, que foram divididos em seis setores: biocombustíveis, terras e florestas, energia, agricultura, indústria e transportes. Os dois últimos setores foram tratados superficialmente, sem detalhes e sem quantificação. A Tabela 1 resume suas metas ao horizonte de 2030 (BRAZIL, 2015).

Tabela 1. Redução de 37\% dos gases de efeito estufa (base 2005) em 2025 e 43\% em 2030.

\begin{tabular}{|c|c|}
\hline \multicolumn{2}{|c|}{ Metas para 2030} \\
\hline Mudança no uso dos solos & Energia \\
\hline Reforçar a aplicação do Código Florestal & $45 \%$ de energias renováveis no mix energético \\
\hline Zero desmatamento ilegal & $\begin{array}{c}\text { De } 28 \% \text { a } 33 \% \text { de energias renováveis (fora hidráulica) } \\
\text { no mix energético }\end{array}$ \\
\hline $\begin{array}{l}\text { Compensação das emissões de GEE devido ao desmata- } \\
\text { mento legal }\end{array}$ & $\begin{array}{c}66 \% \text { de hidráulico e } 23 \% \text { de eólica, solar e biomassa no } \\
\text { oferta de energia }\end{array}$ \\
\hline Restaurar e reflorestar 12 milhões de hectares & $10 \%$ de ganho em eficiência \\
\hline \multicolumn{2}{|l|}{ Recuperar 15 milhões de pastos degradados } \\
\hline \multicolumn{2}{|l|}{ Atingir 5 milhões de hectares em agrossilvipastoris } \\
\hline $18 \%$ de agrocarburantes no mix energético & \\
\hline
\end{tabular}

\section{Desmatamento ilegal zero e desmatamento legal compensado}

O objetivo de "zero desmatamento ilegal" já pertence à política florestal brasileira. A consecução desse objetivo para 2030 pode parecer modesta. No entanto, desde 2012, o desmatamento da Floresta Amazônica está crescendo novamente ${ }^{16}$, principalmente devido à continuação da política de grandes obras como, por exemplo, as barragens hidrelétricas de Belo Monte, no estado do Pará, de Jirau e de Santo Antônio, no estado de Rondônia, e do asfaltamento da Rodovia Cuiabá-Santarém.

Em outubro de 2014, o Brasil recusou-se a participar da Declaração de Nova Iorque sobre Florestas, que sustentava o objetivo de "desmatamento zero", pois, segundo ele, deve-se primeiro distinguir desmatamento legal de desmatamento ilegal. Aqui entendemos seus motivos. A compensação das emissões de $\mathrm{CO} 2$ devido à remoção legal de vegetação, ou seja, "desmatamento zero" em 2030, pode ser interpretada à luz do Código Florestal (e sua efetiva aplicação configura como um objetivo na INDC). Um estudo recente estima que a plena utilização das possibilidades de desmatamento legais oferecidas pelo Código Florestal (RAJÃO; SOARES-FILHO, 2015) permitiria a estabilização da taxa atual de desmatamento nos biomas brasileiros e poderia até atingir $198.000 \mathrm{~km}^{2}$ em 2030.

De onde viriam as compensações referentes a esses desmatamentos legais? A contribuição não é muito explícita. Podemos supor que viriam da restauração e do reflorestamento dos 12 milhões de hectares anunciados. Porém, esses 12 milhões de hectares correspondem à faixa inferior das estimativas das superfícies devastadas (avaliadas entre 12 e 24 milhões de hectares) que devem ser restauradas como parte do Código Florestal.

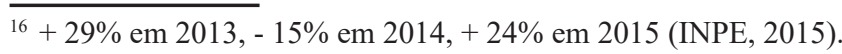




\section{Código Florestal insuficiente para assegurar a conservação}

O Código Florestal permite que os proprietários de terra desmatem a sua propriedade dentro dos limites de $20 \%$ de sua área na Amazônia ( $80 \%$ devem permanecer na vegetação original em "reserva legal" ${ }^{17}$ ) e $80 \%$ no Cerrado (20\% devem permanecer reserva legal). Aqueles que têm uma dívida ambiental, isto é, quem desmatou ilegalmente, acima do percentual permitido, devem regularizar a sua situação. Pequenos agricultores, com menos de quatro módulos fiscais ${ }^{18}$, não estão sujeitos a essa exigência. O programa de regularização oferece várias soluções: restauração in situ, compra ou arrendamento de terra dedicada à conservação, pagamento de um fundo, doação de terras localizadas em unidades de conservação públicas em espera de regularização fundiária ou, finalmente, a compra de títulos em um sistema comercial (aquele que desmatou pode se beneficiar da "sobra" daquele que conservou além do obrigatório por meio da negociação de Cotas de Reserva Ambiental - CRA). O Código Florestal, de fato, possibilita a negociação de certificados transferíveis de cotas de reserva ambiental, que são títulos nominativos correspondentes a uma autolimitação do direito de uso, uma servidão ambiental que representa uma área de 1 hectare de vegetação natural dedicada à conservação.

Porém, esses títulos não oferecem a garantia de conservação das superfícies naturais por duas razões: primeiro, esses títulos podem vir, ironicamente, de áreas já protegidas. Na verdade, muitas propriedades privadas se encontram em unidades de conservação, pois o pagamento das desapropriações não foi realizado por falta de fundos. Trata-se então de regularizar a situação possibilitando que os proprietários quitem suas dívidas ambientais por meio da aquisição de CRAs, que permitem o financiamento dessa compensação. Esses títulos também podem ser provenientes de reservas legais de pequenos proprietários que respeitaram as percentagens de desmatamento autorizadas. Estes podem emitir CRAs de sua reserva legal preservada. Em ambos os casos, os CRAs emitidos não correspondem a um aumento em áreas protegidas. Segundo, teme-se que a oferta de CRAs seja muito abundante, fazendo com que a compensação do desmatamento seja uma operação muito barata. Rajão e Soares-Filho (2015) estimam que a oferta de CRA seria 28 vezes maior do que a demanda na Amazônia e 22 vezes maior no Cerrado. Os "bancos" de trocas de CRA que estão sendo criados, como BVRio e Biofílica ${ }^{19}$, testemunham a dificuldade de unir a oferta dos vendedores aos pedidos dos compradores.

Assim, nos encontramos em uma situação na qual os proprietários podem continuar a desmatar suas propriedades enquanto aqueles que deveriam compensar suas clareiras ilegais poderão recorrer à compra de títulos baratos. Isso deixa claro que apenas a aplicação do Código Florestal não efetiva a luta contra o desmatamento.

\footnotetext{
${ }^{17}$ As áreas de preservação permanente (APPs) ao longo dos rios, topo dos morros, as fontes, etc. devem também ser protegidas.

${ }^{18}$ Um módulo fiscal é uma medida definida pelo Incra em função das características de explorações agrícolas de uma municipalidade. A dimensão de um módulo fiscal varia entre 5 ha e 110 ha, segundo a municipalidade na qual a propriedade se encontra.

${ }^{19}$ A Biofílica diz ter um portfólio de 2,4 milhões de hectares de CRA para negociar. Os primeiros preços vão de 550 reais/ha para a Amazônia a 1.500 reais/ha no Cerrado. Para maiores informações ver: http://biofilica.com.br/boletins/2017_02/boletim_2017_02.html (consultado dia 21 de março de 2017).
} 


\section{Cerrado: primeira vítima do desmatamento legal}

A contribuição brasileira ignora o papel importante do Cerrado como emissor de gases de efeito estufa devido ao seu alto índice de desmatamento. A então ministra da Agricultura, Katia Abreu, e os membros da bancada ruralista ${ }^{20}$ estimulam a expansão agrícola no Cerrado, especialmente na área de Matopiba, na fronteira do Maranhão, Tocantins, Piauí e da Bahia, onde já se pode observar um crescimento do desmatamento. Podemos interpretar essa meta como uma licença para desmatar o Cerrado o máximo que é permitido pelo Código Florestal (ou seja, 80\% da propriedade), $400.000 \mathrm{~km}^{2}$ (dos quais $110.000 \mathrm{~km}^{2}$ já foram reconhecidos como propícios ao cultivo de soja) ficariam assim suscetíveis ao desmatamento legal.

Enquanto a opinião pública internacional está preocupada especialmente com a Floresta Amazônica é importante lembrar a pressão que sofre o Cerrado. Se a Amazônia Legal abrange quase 4 milhões de $\mathrm{km}^{2}$, dos quais $18 \%$ da floresta original já foi desmatada, o Cerrado, cuja área representa metade da Amazônia (2.000.000 km²), foi desmatado em 49\% (IBGE 2012). Desde 2010, o número de quilômetros quadrados desmatados a cada ano no Cerrado é maior do que o da Amazônia.

\section{A agricultura de baixo carbono}

A agricultura e a pecuária respondem agora por $26,8 \% \%^{21}$ das emissões do Brasil. Enquanto isso, o setor poderia proporcionar sumidouros de carbono que absorvem as emissões excedentes. De fato, é desse setor que se esperam os resultados mais tangíveis. Se o Plano ABC, implementado desde 2012, levanta algumas dúvidas sobre sua viabilidade no campo, a promessa de um agronegócio do futuro pode deixar os seus leitores perplexos.

\section{O Plano ABC}

Recuperar 15 milhões de hectares de pastagem degradada e converter 5 milhões de hectares em sistemas agrossilvipastoris são os objetivos apresentados na contribuição brasileira para 2030 (Tabela 2). Esses objetivos já haviam sido incluídos no plano para a consolidação de uma economia de baixo carbono na agricultura (Plano $\mathrm{ABC}$ ), instrumento usado pelo governo brasileiro como parte da Política Nacional sobre Mudança do Clima para 2020. Só o objetivo de sistemas agrossilvipastoris foi revisto em alta, passando de 4 milhões a 5 milhões de hectares, já a superfície de recuperação de pastagem continuou idêntica. O plano visa garantir a melhoria contínua das práticas agrícolas para reduzir significativamente as emissões do setor agropecuário. Ele define seis objetivos e ressalta o potencial de mitigação (Tabela 2).

Um orçamento de 197 bilhões de reais foi considerado necessário para o período de 2010 a 2020. Desses 197 bilhões, 157 tinham vindo de um programa de crédito fornecido pelo Banco Nacional de Desenvolvimento Econômico e Social (BNDES) e outras instituições financeiras, como o Banco do Brasil. Porém na realidade parece ser diferente. Embora os recursos para finan-

\footnotetext{
${ }^{20}$ Os ruralistas constituem um grupo parlamentar de pressão muito importante no Congresso Nacional. Eles defendem os interesses do agronegócio e colocam em xeque as políticas sociais e ambientais do governo que possam restringir o acesso a terras (áreas protegidas, terras indígenas).

${ }^{21}$ Essa porcentagem corresponde às emissões diretas da agricultura e pecuária. Se acrescentarmos as emissões indiretas provenientes do desmatamento dos ecossistemas naturais para a expansão do setor, poderia chegar a $60 \%$ das emissões totais de carbono (IMAFLORA, 2015b).
} 
ciamento da agricultura tenham crescido $^{22}$, o montante gasto em tecnologias de baixo carbono foi de apenas $1,6 \%$ do total do financiamento (IMAFLORA, 2015a).

Tabela 2. Objetivos do Plano ABC para o ano de 2020.

\begin{tabular}{lcc}
\multicolumn{1}{c}{ Processos tecnológicos } & Objetivos para 2020 & $\begin{array}{c}\text { Potencial de mitigação } \\
\text { (milhão tCO2e) }\end{array}$ \\
\hline Recuperação de pastagens degradadas & +15 milhões ha & 83 a 104 \\
Integração agricultura-pecuária-floresta (ILPF) & +4 milhões ha & 18 a 22 \\
Semidireto & +8 milhões de ha & 16 a 20 \\
Fixação biológica de ozônio & $+5,5$ milhões de ha & 10 \\
Floresta plantada & +3 milhões ha & - \\
Tratamento de efluentes da pecuária & $+4,4$ milhões de m $^{3}$ & 6,9 \\
Total & - & 133,9 a 162,9
\end{tabular}

Fonte: Fundação Getúlio Vargas (2012).

Entre 2010 e 2015, o montante total dos empréstimos contratados no âmbito do Programa $\mathrm{ABC}$ foi de apenas 11,15 bilhões, o que demonstra, de acordo com o relatório do Centro de Estudos em Sustentabilidade da Fundação Getúlio Vargas, uma fraca demanda (FGV-EAESP, 2014). Isso poderia ser explicado, em particular, pela burocracia excessiva, pela falta de apoio aos agricultores ou pelo fracasso de agentes financeiros a propor projetos adequados aos pequenos agricultores (IMAFLORA, 2015a). No entanto, o programa não parece ter sido bem-sucedido junto aos grandes agricultores.

De acordo com estudo realizado pela Embrapa e apresentado na COP 21 em Paris, dos 15 milhões de hectares de pastagem degradada, 5 milhões já foram recuperados. Entretanto, dos 4 milhões de hectares para a ILPF, somente 1 milhão de hectares foram realizados. O escopo do plano continua limitado e atrasado para atingir os objetivos até 2020. Isso explicaria o fato do adiamento para 2030? Se outros objetivos do plano atingiram uma taxa de sucesso mais elevada, especialmente o plantio direto com $64 \%$ de realização, esses números demonstram um cumprimento bastante tímido do total das metas. Também é possível identificar uma concentração de recursos financeiros para a recuperação de pastagens degradadas (Tabela 1), pois, em 2014, dos 6,5 bilhões de reais em crédito disponibilizados, 5,5 foram concedidos pelo Banco do Brasil. Desse montante, $68 \%$ foram utilizados para a recuperação de pastagens e $11 \%$ para a implantação do ILPF (FGV-EAESP, 2014).

Entre as técnicas de recuperação das pastagens, as rotações de milho e soja exigem grandes propriedades adaptadas para a utilização de equipamentos agrícolas de grande porte. Técnicas que seriam adequadas à agricultura familiar não fazem parte do Plano ABC. Nós reencontramos assim a dualidade característica da agricultura brasileira que pode vir a ser um obstáculo à realização dos objetivos de mitigação previstos para a agricultura e a pecuária. Desta forma, em uma continuidade implacável, o Ministério do Desenvolvimento Agrário (MDA) ficou responsável pela implementação do Plano Nacional de Agroecologia e Produção Orgânica (PNAPO), que dada sua pequena escala não foi considerado importante o suficiente para integrar a contribuição

${ }^{22}$ Os recursos do financiamento agrícola aumentaram 17\% em 2015/2016 em comparação a 2014/2015. 
nacional brasileira. É o Ministério da Agricultura, Pecuária e Abastecimento (Mapa) que se ocupa dos projetos do agronegócio do futuro.

\section{O agronegócio do futuro}

A delegação brasileira na COP21 foi uma das maiores, contando com 850 participantes, da qual grande parte representava o setor do agronegócio. Isso demonstra uma ampla mobilização do setor cuja atividade representa atualmente 23\% do PIB do Brasil e 25\% dos empregos do País, direta ou indiretamente ligados ao setor (BRASIL, 2016). Essa participação supõe uma vontade de defender os interesses do agronegócio, mas também uma necessidade de renovar a sua imagem internacional (MOREIRA, 2015).

No País em recessão, a exportação de produtos agrícolas é vista como essencial para a manutenção do crescimento econômico tão desejado. Hoje, as exportações dos produtos agrícolas, florestais e agroalimentares correspondem a 46\% do total. Deste modo, assistimos a uma "reprimarização" da economia brasileira, ou seja, uma estratégia que promove a produção e a exportação de matérias-primas em detrimento do desenvolvimento da indústria e dos serviços.

Reforçando essa visão, o Mapa estabeleceu uma meta de aumentar as exportações brasileiras de $7 \%$ para $10 \%$ do comércio internacional de produtos agrícolas e alimentares, de $10 \%$ para $22 \%$ para a União Europeia e de $18 \%$ para $23 \%$ para a China. Para isso, o Brasil pode contar com a disponibilidade de suas reservas de água (as primeiras do mundo) e de terra arável (as segundas, logo atrás do Sudão) que correspondem a 80 milhões de hectares (BRASIL, 2016). Vimos os limites do Código Florestal em matéria de proteção ambiental. Podemos então nos perguntar como o agronegócio pretende aumentar sua produção para atender à demanda comercial e econômica sem expandir áreas de cultivo sobre os ecossistemas naturais, especialmente no Cerrado.

Representantes do lobby agrícola no Congresso Nacional, os ruralistas são cada vez mais numerosos, cerca de 250, e ocupam cargos importantes no governo. A ministra da Agricultura, no momento da COP21, Kátia Abreu, é ex-presidente da Confederação Nacional da Agricultura e Pecuária (CNA), sindicato dos grandes fazendeiros ${ }^{23}$. Pelos discursos feitos no Congresso, mas também pela sua coluna regular na Folha de São Paulo ${ }^{24}$, ela ganhou o prêmio "Motosserra de Ouro", concedido pelo Greenpeace em 2010. Apoiada pelo lobby ruralista, ela defende todas as causas que buscam incentivar maior produção e aumento da área agrícola, como: a extensão de estradas na Amazônia, a expansão das monoculturas, a adoção intensiva de sementes geneticamente modificadas, expansão sobre áreas protegidas e terras indígenas, que são consideradas como bloqueios para a expansão da produção agrícola.

Essa política é ilustrada pela proposta de emenda constitucional PEC 215, que propõe alterar a Constituição para transferir ao Congresso Nacional a decisão final sobre a demarcação das terras indígenas, terras quilombolas e unidades de conservação. Atualmente, apenas o Poder Executivo, apoiado por seus órgãos técnicos, pode decidir sobre essas demarcações. Hoje, de

\footnotetext{
${ }^{23}$ Em maio de 2016, quando houve mudança no governo, Blairo Maggi, um dos maiores produtores de soja no mundo e igualmente vencedor do prêmio Motosserra de Ouro, substituiu Kátia Abreu como ministro da agricultura. Assim, podemos apenas esperar uma continuação da política já iniciada.

${ }_{24}$ Textos disponíveis no site do jornal: http://wwwl.folha.uol.com.br/colunas/katiaabreu/ (consultado no dia 19 de março de 2017).
} 
acordo com a Fundação Nacional do Índio (Funai), 12,2\% do território brasileiro é reservado para os territórios indígenas, cuja maioria está localizada na Amazônia. No entanto, 45\% da população indígena não está em território amazônico. Assim, no estado de Mato Grosso do Sul conflitos extremamente violentos surgem entre fazendeiros e indígenas que se encontram em situação de extrema dificuldade. Entre 2003 e 2014, 309 índios foram assassinados, de acordo com o relatório sobre a violência contra os povos indígenas no Brasil (CONSELHO INDIGENISTA MISSIONÁRIO, 2014).

A Coalizão Brasil pelo Clima, Florestas e Agricultura

Formada em dezembro de 2014, essa coalizão é composta por uma diversidade de atores. Ela reúne empresas de horizontes muito diversos (Natura, Fibria, Carrefour, Cargill e Monsanto), assim como associações, uniões e empresas do agronegócio (SRB, Unica, Abag, Amaggi), totalizando 120 organizações no total.

Os side events organizados pela Coalizão, ou aqueles dos quais seus representantes participaram, serviram de espaço para afirmar seus bons resultados tanto econômicos como ecológicos e também para exibir sua aliança. Nós podemos identificar duas grandes linhas: defesa e promoção do novo Código Florestal; e o reconhecimento dos esforços realizados pelo agronegócio pela implementação de uma agricultura tecnológica "intensiva e sustentável" que dá ao Brasil os trunfos para vir a ser um líder internacional.

Fonte: http://coalizaobr.com.br/2016/ (consultado dia 19 de março de 2017).

A forte participação do setor do agronegócio na COP21 revelou uma contradição entre o discurso apresentado para a comunidade internacional e a realidade nacional. Os eventos organizados tanto na embaixada do Brasil quanto no Le Bourget, assim como os eventos apresentados pela Coalizão Brasil pelo Clima, Florestas e Agricultura, no quadro abaixo, colocam o setor em cena de modo a ressaltar seus pontos fortes. $\mathrm{O}$ agronegócio brasileiro teria então incorporado em seu discurso, e talvez até mesmo em algumas de suas práticas, as críticas socioambientais que recebeu, a fim de reconstruir a sua imagem internacional manchada por má reputação devido as suas práticas (DEMEULENAERE; CASTRO, 2015).

Os benefícios apresentados são confusos: sucesso na luta contra o desmatamento e as emissões de gases de efeito estufa, o novo Código Florestal, um clima que permite várias colheitas por ano, água abundante, tecnologia de ponta desenvolvida pela Empresa Brasileira de Pesquisa Agropecuária (Embrapa), uma reatividade empresarial (o agricultor sabe o quê, onde e quando plantar para obter melhores resultados), uma energia a partir de fontes limpas, como a energia hidrelétrica ou de biocombustíveis e, finalmente, enormes reservas de terra livre e uma população que aceitaria e apoiaria o agronegócio para a sua produção de riqueza.

Fala-se, então, de uma "revolução no agronegócio" que buscaria abandonar as técnicas convencionais, consideradas muito exigentes em recursos naturais, para adotar novas práticas fundadas em uma suposta "intensificação sustentável”. A questão central continua sendo a de assegurar o aumento da produção para alimentar uma população mundial em crescimento. Para isso, a produção desse "agronegócio do futuro" deveria ser reconhecida pelos mercados internacionais (para obter os melhores preços para os seus produtos) de maneira a financiar os custos dessa "intensificação ecológica" (estimada em 100 bilhões de dólares ao longo de 20 anos). 
A contribuição brasileira se apresenta majoritariamente como uma "agricultura do futuro", perfeitamente alinhada com o discurso transmitido na COP21 sobre a Climate Smart Agriculture, particularmente sobre a capacidade dos solos agrícolas de armazenar carbono. Dadas as dificuldades na redução das emissões, é preciso encontrar uma solução com sumidouros de carbono para chegar em "zero emissões líquidas" do Acordo de Paris. Ficou claro, assim, que o foco mudou das florestas para a agricultura, que teria um papel central nas tecnologias de captura e armazenamento de carbono nos solos (como o Projeto 4/1000 apresentado pelo governo francês). Com a recuperação de pastagens degradadas e integração agrossilvipastoril, o Observatório do Clima estima que as emissões do setor agrícola brasileiro poderão ser reduzidas em $50 \%$ graças ao sequestro de carbono pelo solo (SISTEMA DE ESTIMATIVA DE EMISSÃO DE GASES DE EFEITO ESTUFA, 2015).

É nesse contexto agrícola que convém analisar o objetivo de aumentar para $18 \%$ a quantidade de biocombustíveis representados na matriz energética. Esse objetivo supõe alto investimento em inovação, como, por exemplo, a alta tecnologia das usinas de etanol de segunda geração, das quais se espera uma produtividade três vezes superior, com menos consumo de água, menos impacto nos solos e com custos de produção competitivos frente ao preço elevado do barril de petróleo (aproximadamente 49 dólares). O BNDES já financiou duas usinas (existem apenas cinco no mundo). A coalizão estima que, para que o etanol substitua $10 \%$ do consumo mundial de gasolina, seriam suficientes 7 milhões de hectares, enquanto a produção de etanol de primeira geração demandaria 25 milhões (MOREIRA 2015). É clara aqui a visão da alta tecnologia, ignorando os custos sociais e o destino dos trabalhadores da cana nas explorações agrícolas não mecanizadas.

\section{A energia e outros setores}

Diante da afirmação do poder do agronegócio na luta contra o efeito estufa, as metas do setor de energia parecem tímidas. Por exemplo, se encontramos na contribuição brasileira uma vontade expressa em termos vagos para melhorar a eficiência energética nos setores da indústria e dos transportes, não encontramos nenhuma referência ao setor da habitação e, de maneira geral, a um programa global de gestão de energia. No entanto, vimos (Figura 1) que o principal problema das emissões de gases de efeito estufa é agora de responsabilidade do setor de energia (responsável por $30,7 \%$ das emissões).

As emissões aumentaram em 35\% entre 2005 e 2012. O ritmo continua, o aumento foi de $6 \%$ em 2014, apesar do fraco crescimento econômico. O consumo energético nos transportes, principal posto do setor, é $60 \%$ maior do que a média dos demais países chamados de emergentes (BRICS). No entanto, a contribuição permanece vaga, sem oferecer mais detalhes para promover medidas eficazes e melhorar a infraestrutura e o transporte público urbano. Nós não encontramos nenhum questionamento sobre a decisão de favorecer o transporte individual privado, apoiando a indústria automobilística, os subsídios aos motores a diesel e a gasolina, e isenção de impostos sobre carros.

Em seguida, pode-se perguntar se as medidas da contribuição serão suficientes para finalmente erradicar essa tendência ascendente. Quanto aos outros objetivos, a meta de $45 \%$ de energias renováveis no mix energético foi alcançada em 2004 e essa percentagem é mantida desde 
então. O desafio está em aumentar o uso de fontes de energia não fósseis para fontes distintas da hidrelétrica, que hoje representa dois terços da oferta.

A preocupação em salientar que esforços serão feitos para desenvolver as energias renováveis ,"outra que a hidráulica", não convence, pois a atual política de grandes barragens permanece imprescindível para suprir a demanda de energia e as necessidades da população. Assim, a participação da matriz hidrelétrica continuará a girar em torno de $66 \%$ do total.

O uso maciço das energias renováveis entra em contradição com o Plano Decenal de Energia (PDE, 2015-2024), que prevê que 70\% dos investimentos no setor se concentrarão em combustíveis fósseis (gás, gás de xisto, óleo...). Ele também coexiste com a continuação dos leilões de blocos para a exploração de petróleo e gás, especialmente perto de unidades de conservação e terras indígenas da Amazônia, com impactos conhecidos sobre o desmatamento.

Note que não se toca na contribuição sobre o uso da energia nuclear, enquanto uma terceira parcela do complexo nuclear de Angra dos Reis está programado e que mais outras quatro usinas nucleares estão sendo consideradas. Também não se fala na exploração das reservas de petróleo em águas profundas (pré-sal), que ainda tem provocado grandes esperanças e gerado conflito na distribuição de royalties prevista para os estados litorâneos e os do interior. A exploração do petróleo foi finalizada? O Acordo de Paris, para ser mantido, exige que $80 \%$ das reservas de energia fósseis permaneçam intactas, ou que a queda do preço do petróleo faça com que os custos de produção não sejam compensados, por exemplo, um barril custando 40 dólares.

\section{Conclusão}

O estudo da contribuição brasileira nos permitiu dar conta, além dos objetivos simples de redução das emissões de gases de efeito estufa, da imagem que o País pretende passar na cena internacional. Nós testamos essa afirmação identitária fundada na cultura política do Brasil frente às situações concretas.

O exercício das contribuições nacionais (INDC) deveria permitir aos países que se juntassem na luta global contra as alterações climáticas, avaliado principalmente em termos de esforços de redução de emissões de GEEs. No entanto ainda é cedo para avaliar os esforços do instrumento no seio das negociações climáticas e para saber se as contribuições serão a base do novo regime climático. De qualquer forma, o total das reduções anunciadas conduzirá a um limiar amplamente superior ao de $2{ }^{\circ} \mathrm{C}$ de aquecimento. A soma dos financiamentos solicitados também continua inferior aos 100 bilhões de dólares prometidos para o Fundo Verde para o clima. O sucesso do Acordo de Paris se medirá na possibilidade de aumentar os objetivos nacionais no que diz respeito às reduções das emissões e aos financiamentos que serão desbloqueados para os atingir.

No entanto, poderíamos esperar encontrar nas contribuições um início de discussão sobre os modos de produção e de consumo, pelo menos um embrião de uma política de transição energética. Mas o Brasil permanece em uma lógica simples de descarbonização, sem alterar sua trajetória de dependência, sem uma mudança real em sua política. Se esse é o caso da maioria dos países, não é o caso da China e da Índia, que devem achar energias de substituição ao carvão do qual elas dependem. Em razão do crescimento demográfico e de sua urbanização, a Índia deverá 
tomar as medidas mais radicais para ter sucesso na luta mundial contra a mudança climática, "construir um país novo em 2030", como foi dito na sua contribuição (AUBERTIN; BENABOU, 2015).

A contribuição do Brasil se inscreve na cultura política de um modelo de desenvolvimento centralizado que repousa sobre a extensão do agronegócio, sobre as monoculturas de exportação em larga escala (soja e cana-de-açúcar), intensificando a pressão sobre as terras indígenas e sobre as unidades de conservação e prosseguindo na realização de grandes infraestruturas causadoras de grandes impactos socioambientais, como a barragem de Belo Monte.

A política climática não foi uma oportunidade de desafiar o modelo de desenvolvimento desigual gerado por uma economia a velocidades múltiplas, de promover a agricultura em pequena escala, de acabar com a destruição do ecossistema do Cerrado e repensar sistemas de transporte que favorecem o carro privado.

Por sustentar sua imagem de ator das lutas contra as alterações climáticas, o Brasil foi beneficiado por um período de redução do desmatamento na Amazônia. Ele aposta hoje no agronegócio do futuro, altamente técnico, e no desenvolvimento de energias renováveis. Levantamos várias questões quanto ao realismo dessa contribuição, sobretudo desde a publicação do terceiro inventário das emissões entregue à secretaria da UNFCCC, que exigiria, para que o Brasil mantivesse seus engajamentos, uma redução nas emissões de 2020 acima dos $37 \%$ anunciados. O País realmente tem a possibilidade de controlar suas emissões e de multiplicar as energias renováveis em tão pouco tempo para responder à demanda crescente de energia? Por isso, ele deverá empreender uma reflexão sobre a matriz energética e habilitar programas multissetores de economia de energia que não encontramos na contribuição. O desafio será, após sair da recessão e da crise política, o de abandonar um modelo econômico fundado nas exportações de matérias-primas para restabelecer a ligação com um desenvolvimento mais diversificado e socialmente mais equilibrado. A recente mudança de governo e os turbilhões políticos que acompanham o Brasil nos últimos meses ilustram as dificuldades de mudar essa cultura política.

\section{Referências}

AUBERTIN, C.Deforestation control policies in Brazil: sovereignty versus the market. Forests, Trees and Livelihoods, v. 24, n. 3, p. 147-162, 2015.

AUBERTIN, C.; BENABOU, S. Staging political cultures. Analysis of India's and Brazil's INDCs. Communication au Workshop international organisé dans la cadre de la COP 21 par l'UMR PALOC (IRD/ MNHN) et l'Université John Hopkins Climate Change and its Challenges to the Scholarly Habitus. Paris: Muséum national d'histoire naturelle, 12 dez. 2015.

AUBERTIN, C.; DAMIAN, M.; MAGNY, M.; MILLIER, C.; THEYS, J.; TREYER, S. (Ed.). Les enjeux de la conférence de Paris: penser autrement la question climatique. Natures, Sciences, Sociétés, v. 23, juin 2015. Suppl.

BRASIL. Ministério da Agricultura Agropecuária e Abastecimento. Agronegócio brasileiro: perspectivas 2016 CDES. Brasília, DF, 2016. Disponível em: http://www.agricultura.gov.br/arq_editor/ PRESIDENTE_V_Final1.pdf. Acesso em: 24 mar. 2017. 
BRASIL. Ministério da Agricultura Agropecuária e Abastecimento. Plano Setorial de Mitigação e Adaptação às Mudanças Climáticas para a Consolidação de uma Economia de Baixa Emissão de Carbono na Agricultura - Plano ABC. Brasília, DF, 2012.

BRASIL. Ministério da Ciência e Tecnologia. Segunda Comunicação Nacional do Brasil à ConvençãoQuadro das Nações Unidas sobre Mudança do Clima. Brasília, DF, 2010a. 2 v.

BRASIL. Presidência da República. Lei $\mathbf{n}^{\circ} \mathbf{1 2 . 1 8 7}$, que institui a Política Nacional sobre Mudança do Clima - PNMC. Brasília, DF, 2009. Disponível em: http:/www.planalto.gov.br/ccivil_03/_ato20072010/2009/lei/112187.htm. Acesso em: 18 fev. 2016.

BRASIL. Presidência da República. Lei $\mathbf{n}^{\mathbf{9} 9.985}$, que institui o Sistema Nacional de Unidades de Conservação da Natureza - SNUC. Brasília, DF, 2010b. Disponível em: http://www.planalto.gov.br/ccivil_03/LEIS/L9985.htm. Acesso em: 01 nov. 2020.

BRAUD, P. Sociologie politique. Paris: LGDJ, 2008.

BRAZIL. Intended Nationally Determined Contribution. Towards achieving the objective of the United National Framework Convention on Climate Change. 2015. Disponível em: http://www4.unfecc.int/ submissions/INDC/Published\%20Documents/Brazil/1/BRAZIL\%20iNDC\%20english\%20FINAL.pdf. Acesso em: 18 fev. 2016.

CONSELHO INDIGENISTA MISSIONÁRIO - CIMI. Relatório: violência contra os povos indígenas no Brasil - dados de 2014. Disponível em: http://cimi.org.br/pub/Arquivos/Relat.pdf. Acesso em : 01 nov. 2020.

CUCHE, D. La notion de culture dans les Sciences sociales. Paris: La Découverte, 2001.

DEMEULENAERE, E.; CASTRO, M. Modèles de verdissement de l'agriculture et acteurs en compétition à Rio+20. In: REGARDS croisés sur Rio+20. La modernisation écologique à l'épreuve. Paris: Editions CNRS, 2015. p. 185-212.

FOYER, J. ; MORENA, E. Une recherche collaborative pour analyser la conférence Paris Climat 2015 : le projet ClimaCOP. Natures, Sciences, Société, v. 23, p. 275-279, 2015.

FUNDAÇÃO GETÚLIO VARGAS - FGV-EAESP. Centro de Estudos em Sustentabilidade. SDC apresenta resultados do Plano ABC. São Paulo, 2014b. Disponível em: https://abccapacitacao.wordpress. com/2014/04/09/sdc-apresenta-resultados-do-plano-abc/Acesso em: 01 nov. 2020.

INSTITUTO BRASILEIRO DE GEOGRAFIA E ESTATISTICA - IBGE. Indicadores de desenvolvimento sustentável. Brasília, DF, 2012. (Estudos \& Pesquisas).

INSTITUTE FOR SUSTAINABLE DEVELOPMENT AND INTERNATIONAL RELATIONS - IDDRI. 2015. Beyond the numbers: understanding the transformation induced by INDCs. Paris: MILES Project Consortium, 2015. 80 p. (Studies $\mathrm{N}^{\circ} 05 / 2015$ ).

INSTITUTO DE MANEJO E CERTIFICAÇÃO FLORESTAL EAGRÍCOLA-IMAFLORA. Documento de análise: evolução dos gases de efeito estufa no Brasil (1970-2013) setor da Agropecuária. São Paulo: Observatório do Clima, 2015a. Disponível em: https://www.imaflora.org/downloads/biblioteca/55ca3a26a856a_agropecuaria_2015.pdf. Acesso em: 01 nov. 2020.

INSTITUTO DE MANEJO E CERTIFICAÇÃO FLORESTAL E AGRÍCOLA - IMAFLORA. Financiamento agrícola para a redução das emissões na agropecuária brasileira responde a 1,6\% dos recursos totais. 2015b. Disponível em: http://imaflora.blogspot.fr/2015/08/financiamento-agricola-para-reducao-das.html. Acesso em: 1 nov. 2020. 
INSTITUTO NACIONAL DE PESQUISAS ESPACIAIS - INPE. Projeto PRODES: monitoramento da Floresta Amazônica brasileira por satélite. 2015. Disponível em: http://www.meioambiente.am.gov.br/ wp-content/uploads/2015/08/BOLETIM_PRODES2013_2014_RETIFICADO.pdf Acesso em: 1 nov. 2020 .

MOREIRA, A. Europa vê agronegócio brasileiro como vilão ambiental. Valor Econômico, 09 dez. 2015. Disponível em: http://www.valor.com.br/internacional/4348692/europa-ve-agronegocio-brasileiro-como-vilao-ambiental. Acesso em: 13 fev. 2016.

RAJÃO, R.; SOARES-FILHO, B. Policies undermine Brazil's GHG goals. Science, v. 350, p. 519, 2015. Disponível em: http://csr.ufmg.br/cra/. Acesso em: 24 mar. 2017.

ROSANVALLON, P. Le modèle politique français: la société civile contre le jacobinisme de 1789 à nos jours. Paris: Seuil, 2004.

SIRKIS, A.; HOURCADE, J. C.; STUDART, D. D. R.; GALLAGHER, K.; PERRISSIN-FABERT, B.; VEIGA, J. E. da; ESPAGNE, E.; STUA, M.; AGLIETTA, M. Moving the Trillions a debate on positive pricing of mitigation actions. s.1.: Brasil no Clima, 2016. Disponível em: http://www.centrobrasilnoclima.org/PDFs/Book_Moving-in-the-Trillions_final.pdf. Acesso em: 24 mar. 2017.

SISTEMA DE ESTIMATIVA DE EMISSÃO DE GASES DE EFEITO ESTUFA - SEEG Brasil. Emissões totais. 2015. Disponível em: http://plataforma.seeg.eco.br/total_emission. Acesso em: 24 mar. 2017. 